\title{
Toss and Turn or Toss and Stop? A Coin Flip Reduces the Need for Information in Decision-Making
}

\author{
Maria Douneva $^{\mathrm{a} *}$, Mariela E. Jafféa ${ }^{\text {, Rainer Greifeneder }}{ }^{\mathrm{a}}$ \\ ${ }^{a}$ University of Basel, Switzerland
}

*Corresponding author at: University of Basel, Department of Social Psychology,

Missionsstrasse 64a, 4055 Basel, Switzerland.

E-mail addresses: maria.douneva@unibas.ch (Maria Douneva), mariela.jaffe@unibas.ch (Mariela E. Jaffé), rainer.greifeneder@unibas.ch (Rainer Greifeneder).

The authors thank Rebekka Holzer for her help in conducting the studies, and Caroline Tremble for language corrections.

This research was supported by grant 100019_159445 of the Swiss National Science Foundation. 


\begin{abstract}
When deciding between two options, settling can be difficult if one option is superior on one dimension but inferior on another. To arrive at a conclusion, people may gather further information, thereby running the risk of prolonging or blocking the decision-making process or even making suboptimal decisions. Here, we suggest that random decision aids may prove fruitful by reducing the need for further information. Five experiments (total $N=997$ ) examined how information need is influenced after making a preliminary decision between two options and then receiving a suggestion from a random decision aid (a coin flip). Across studies, coin participants are less likely to request additional information (Study 1 and two follow-up studies, combined $p=.021$ ) and indicate a lower need for additional information (Study $2, p=.023$, and Study 3, $p=.001$ ) compared to a control condition without a coin flip. Interestingly, participants do not necessarily adhere to the coin but stick to their preliminary decision as much as or even more than the control group, suggesting that the decision aid does not determine the decision outcome. This is true for hypothetical decisions between changing versus maintaining the status quo without an objectively correct solution (Studies 1, 1b, and 1c), for a decision between two options with an objectively correct solution (Study 2), and for a real monetary decision without an objectively correct solution (Study 3). Random decision aids may thus help to avoid decision blocks or the collection of too much information.
\end{abstract}

Keywords:

decision-making, information need, random device, coin flip 


\section{Toss and Turn or Toss and Stop? A Coin Flip Reduces the Need for Information in Decision-Making}

Imagine that you receive two job offers after applying for several jobs. One promises an average salary and good work-life balance, while the other promises an extraordinary salary but comes with a high workload. In other words, one option is superior to the other on one dimension (work-life balance) but inferior on another (salary). This attribute conflict is inherent to many real-life decision situations (Carpenter, Yates, Preston, \& Chen, 2016). The notion of conflict implies a negative connotation, and being undecided is indeed often experienced as aversive (van Harreveld, Rutjens, Rotteveel, Nordgren, \& van der Pligt, 2009). People therefore try to resolve this state using various strategies (Carpenter et al., 2016), for example, by writing down arguments or asking friends, effectively resulting in more information about the decision options.

Decision aids, such as making lists or asking for advice, are often methods to gather information. They are expressions of the widely held assumption that the more information people possess, the better their resulting decision can be (see Peters, Klein, Kaufman, Meilleur, \& Dixon, 2013), as put forward by classic economic theories such as rational choice theory (von Neumann \& Morgenstern, 1947). This assumption is also reflected in the strategies people employ to make everyday decisions. In a study unrelated to this paper (materials and results available upon request), we asked 149 participants which decision aids they would use to decide between movies, restaurants, hotels, and so forth. Two frequently mentioned decision aids were asking friends or family (61\% of participants) and thinking about or making a list of pros and cons (50\% of participants), suggesting that collecting information is a valued decision-making strategy. People indeed prefer to have more rather than less information in decision-making settings, even when that information has no effect on the decision (Redelmeier, Shafir, \& Aujla, 2001), or when the amount of information lowers decision performance (O'Reilly, 1980). One explanation for these behaviors might be that having more information fosters the feeling of 
being in control (even if only illusory), which is considered to be a fundamental human motive (Kelley, 1971; Skinner, 1996).

Although accumulating information is desirable, it is time-consuming and thus not always feasible (Halamish \& Liberman, 2017). Furthermore, one may end up having too much information, which may result in negative consequences for both the decision outcome and the decision-maker (see Fukukura, Ferguson, \& Fujita, 2013, p. 658 for an overview). Finally, the need to gather further information can also result in not making a decision at all, a situation colloquially termed analysis paralysis. It describes the "inability to respond effectively to a situation due to an over-analytical approach or to an excess of available information" (The Oxford English Dictionary, 1989, emphasis added).

One way of ending analysis paralysis can be to let chance decide. A random decision device does not provide arguments or any actual information about the decision options. Instead, it offers a clear solution. In this paper, we investigate how information need is influenced when people are confronted with a suggestion coming from a random decision device before they settle for an option. In contrast to most previous research, we do not understand the random device as a decider (which effectively determines the decision), but as an aid supporting autonomous decisions. Before we outline our perspective, we will cover literature on random decision devices more generally.

\section{An Alternative to Deciding by Oneself: Using Randomizers for Decisions}

A vast body of literature suggests that people generally like to make decisions themselves: People find it inherently rewarding to have choice (Leotti \& Delgado, 2011), people tend to have an aversion to uncertain outcomes (Simonsohn, 2009), choosing provides a sense of control (Leotti, Iyengar, \& Ochsner, 2011), and choosing results in more enjoyment and higher task performance in the chosen activities (compared to when not being able to choose; Botti \& Iyengar, 2004). However, this preference for choosing is seemingly eliminated or even reversed under certain circumstances: for instance, when choice options are very similar 
(Botti \& McGill, 2006), when having to choose between undesirable options (Botti \& Iyengar, 2004), when one might regret the decision (Steffel \& Williams, 2017), when one wants to avoid responsibility and blame (Steffel, Williams, \& Perrmann-Graham, 2016), and/or when choosing for others (Leonhardt, Keller, \& Pechmann, 2011). People then more often prefer to delegate the decision, for example to another person.

One special way of delegating decisions is to let chance decide. A well-known example of this strategy is to flip a coin, which is seen as a fair device to determine an outcome (Eliaz \& Rubinstein, 2014; Keren \& Teigen, 2010). Still, people seem ambivalent regarding the use of a coin flip. Although they see coin flips as fair, they are generally rather reluctant to use them (Keren \& Teigen, 2010). At the same time, there are specific situations in which people prefer to flip a coin: when the coin flip increases procedural fairness by correcting a previous bias (Bolton, Brandts, \& Ockenfels, 2005), when resources are scarce and cannot be divided (Beattie et al., 1994; Gordon-Hecker et al., 2017), or when people experience a moral conflict between self-serving and prosocial behavior (Lin \& Reich, 2018). Coin flips, along with other random devices, have received particular attention in research on cheating and immoral behavior (see Gino, Norton, \& Weber, 2016, for a review), and appear to be able to provide justification for engaging in these behaviors (e.g., Batson, Kobrynowicz, Dinnerstein, Kampf, \& Wilson, 1997; Shalvi, Dana, Handgraaf, \& De Dreu, 2011).

When people let chance decide by means of flipping a coin and simply do as suggested by the coin, the coin acts as decider (instead of the person). This is how coin flips have been treated in the literature described above. However, oftentimes people realize that they do not like the outcome of the coin flip, or are relieved that a specific outcome shows, and then make their decision independently of the coin. This second case - not simply doing what the coin says but rather realizing what one prefers after leaving the decision up to chance - might even be the more common case, at least in the context of personal decisions. An online field study with more than 20,000 observations (Levitt, 2016) supports this reasoning that coin flips rarely 
act as deciders, but rather as decision aids when it comes to own decisions. In Levitt's study, people who had difficulties making a certain decision in the form of "Should I do X?" were invited to virtually flip a coin and instructed to adhere to its outcome within the following months. Although participants willingly used the coin, only $63 \%$ of them did what the coin suggested, and even less so when the decision at hand was important (e.g., quitting a job, ending a relationship). Importantly, however, the coin still had an impact: When told by the coin to make a change (vs. to maintain the status quo), participants were much more likely to make a change and were happier several months later. One way to look at these findings is that in decision situations of the form "Should I do X (or should I keep the status quo)?", many participants might have a preference to act (vs. not to act), but might not be confident enough to act upon this preference to make a change (see findings about status quo bias, e.g., Eidelman \& Crandall, 2012; Ritov \& Baron, 1992; Samuelson \& Zeckhauser, 1998). If they, however, received a clear recommendation by the coin flip, this recommendation might have made their (assumed) preference to make a change clearer so that they more often acted accordingly.

The author concludes that "some part of the impact of the coin toss is to accelerate changes that would have happened anyway, but at a later date" (Levitt, 2016; p. 7). We resonate with this conclusion: When the coin does not act as a decider, it may still act as a decision aid that influences downstream processes, such as the search for information.

\section{Information Search When Using Randomizers for Decisions}

Previous work has identified various factors that influence information search in the decision-making context, for example, making a decision for oneself or for someone else, making a decision for the near or distant future (Halamish \& Liberman, 2017), experience with or prior knowledge of a decision situation, situational involvement, the desire for an optimal decision, or personality variables such as the need for cognition (Schmidt \& Spreng, 1996). We suggest that random decision devices affect information search, too. In particular, we assume 
that random decision devices reduce information search. We base this assumption on the following arguments:

First, even subtle cues such as closing the menu after having decided on a meal can trigger choice closure. Choice closure is defined as the psychological process by which people perceive a decision to be final (Gu, Botti, \& Faro, 2013). A coin flip, which is normally used to make a straightforward and quick decision, could therefore also signal that a decision is final, which would provide a reason to stop collecting information.

Second, the notion of choice closure also resonates with research on the implementation of decisions. The predecision phase (i.e., while thinking abstractly about a decision) is characterized by open-mindedness in processing decision-relevant information, while the decision phase is characterized by practical considerations regarding the implementation of the decision (Beckmann \& Gollwitzer, 1987; Heckhausen \& Gollwitzer, 1987). A coin flip might signal a transition from the predecision to the decision phase, thereby reducing openmindedness. In other words, flipping a coin might signal that no further information is needed, and that one is ready to "cross the Rubicon." A coin flip might additionally enhance the mental simulation of engaging in a behavior, thereby lowering information search because again, it might feel like the decision has already been made. Solely fantasizing about a future behavior (vs. imagining the steps that need to be taken) indeed decreases the likelihood of displaying that behavior (Oettingen, 2012; Oettingen \& Schwörer, 2013).

Third, a transition from the predecision to the decision phase can also be described as moving along the continuum from hypotheticality to reality. Put differently, flipping a coin might bring people closer to an actual decision. Evidence accrued within the framework of Construal Level Theory (Liberman \& Trope, 2008; Trope \& Liberman, 2010) has documented that people desire less information in "near" compared "far" conditions, for example, when deciding for themselves versus for a friend or when deciding for the near versus the distant future (Halamish \& Liberman, 2017). 
Lastly, when people have a preference, they know that additional information could sway them away from this preference and therefore sometimes even choose to ignore information (Woolley \& Risen, 2018). This information avoidance to protect a decision is even greater when the preference is stronger and before a decision is made (vs. after it is made, Woolley \& Risen, 2018). If people's preferences become clearer through a coin flip, this may reduce their search for further information.

All of these findings allow for the intriguing conclusion that a coin flip may reduce information search. We test this notion in what follows.

\section{Overview of the Present Studies}

Across five online studies (Study 1 with two follow-up studies, Study 2, and Study 3), we test the hypothesis that seeing the outcome of a coin flip reduces information search before making a final decision. We operationalize information search as both the need for information that people express as well as the amount of information they consult before making a final decision.

The overall procedure is the same in all studies. Step 1: We present participants with decision information. Step 2: We ask participants to make a preliminary decision. Step 3: We offer participants further information before making their final decision. Crucially, we introduce a coin flip for some participants before Step 3, which is explicitly described as nondeterminant (i.e., people can choose independently of the coin's suggestion).

We report all measures, manipulations, and exclusions. We determined sample sizes prior to data collection through power analyses with G*Power (Faul, Erdfelder, Lang, \& Buchner, 2007), using small to medium-sized effects for the respective analyses and designs (since effects of this magnitude are typical for social psychological research; Richard, Bond, \& Stokes-Zoota, 2003), a desired power of .80, and an alpha level of .05. Whenever two different analyses were necessary to test predictions (e.g., ANCOVA and chi-square test), we based data collection on the power analysis indicating a higher required sample size. We always recruited 
slightly more participants than indicated by the power analysis to account for a potentially reduced sample size after applying predefined exclusion criteria (self-reported carefulness, selfreported reasons to exclude data, language proficiency). All data, analyses, and materials are stored in an online repository (https://bit.ly/2ljvoKP).

\section{Study 1}

In Study 1, participants decided whether or not to prolong the contract of a store manager based on information about his past performance, and they could request further information in the form of fictitious search engine results. We hypothesized that compared to a control condition, participants watching a coin flip would want further information less often and would check to read fewer pieces of information.

\section{Method}

Participants and design. For this study, we recruited 170 German participants via the online platform Clickworker (for a review on Clickworker data quality, see Lutz, 2016), offering a compensation of $€ 0.75$ ( $\$ 0.93$ at that time) for a median participation time of 6 minutes. Based on our previously defined exclusion criteria, we excluded the data of seven participants (participants who indicated low carefulness while filling out the study, i.e., a score below five on a nine-point scale, $n=5$; participants who indicated that their data should not be used, $n=2$ ). The final sample comprised 163 participants ( 85 male, 77 female, one undisclosed; $\left.M_{\text {age }}=37.94, S D_{\text {age }}=11.33\right)$. A sensitivity analysis with $\mathrm{G}^{*}$ Power showed that our sample size was sufficient to detect effect sizes of Odds Ratio $(\mathrm{OR})=.33$ or larger with $80 \%$ power.

There were two conditions in which participants watched a coin flip: one condition with a coin outcome in line with participants' preliminary decision (coin-congruent condition), and one condition with a coin outcome opposite to participants' preliminary decision (coinincongruent condition). We did not expect to find differences in information search between these two coin groups, but other variables might be differentially affected, which we report in 
an exploratory fashion. Participants were randomly assigned to the coin-congruent $\left(n_{\text {congr }}=53\right)$, the coin-incongruent $\left(n_{\text {incon }}=55\right)$, or the control condition $\left(n_{\text {control }}=55\right)$.

Materials and procedure. Participants learned that their task was to decide whether the contract of a store manager should be extended or not on the basis of information describing his earlier performance. The vignette has been successfully employed in several studies on selective exposure to information (e.g., Fischer et al., 2011; Fischer, Fischer, Weisweiler, \& Frey, 2010; Mojzisch, Schulz-Hardt, Kerschreiter, \& Frey, 2008) and was intended to present participants with an ambiguous decision problem. After reading the vignette, participants were asked to preliminary decide whether or not the contract should be extended (binary choice) while being explicitly informed that there would be more information available and that they could later change their decision. We furthermore asked for their preliminary decision certainty (from $0 \%$ to $100 \%$ certain).

Participants in the coin-congruent and in the coin-incongruent condition were then told that because some people think that the decision at hand is difficult, we offer them the possibility of virtually flipping a coin. This could help to make a decision, but they still may decide independently of the coin flip's outcome. Participants further learned about the two possible coin outcomes: heads meant that the contract should be extended, whereas tails meant that the contract should not be extended. Coin participants then saw a coin flip animation and an outcome that suggested either the same course of action as they had previously indicated (coin-congruent condition) or an outcome that suggested the other course of action (coinincongruent condition). Participants in the control condition saw a rotating hourglass animation and were told to shortly wait while the next study part was loading.

All participants indicated whether they wanted further information before making their final decision (yes/no). If they indicated no, they proceeded to the final decision. If they indicated yes, they were asked on the next page to imagine having performed a Google search on the manager and were presented with snippets of 10 fictitious search results (e.g., restaurant 
or product reviews he had written). We had pretested the material on an independent sample $(N=15)$ to ensure that participants could infer the valence of the information from the snippets but that the information pieces were not very relevant for the decision about the contract. We asked participants to select the results they would like to read in full (from 1 to 10). The chosen snippets were displayed on the following page.

Next, participants were asked to make their final decision (yes/no), to indicate their decision certainty ( $0 \%$ to $100 \%$ certain), and the subjective difficulty of making the final decision (Likert-scale, 1 = very difficult to 7 = very easy, later reverse-coded). Participants who had asked for additional information saw the corresponding pieces of information a second time and indicated how relevant each was for their decision (Likert-scale, $1=$ not relevant to $7=$ very relevant).

Finally, we asked participants how carefully they had filled out the survey, whether there was a reason to not use their data, and to indicate their gender and age. Upon completion, participants were provided with the possibility to comment on the study, were thanked for their participation, and provided with the necessary information for compensation.

\section{Results}

In the present sample, the decision situation was not as ambiguous as expected: The majority $(81 \%)$ of participants opted for not prolonging the contract, participants were overall quite certain regarding their final decision $(M=9.01, S D=1.63$ on a 11 -point scale, i.e. $80 \%$ certain on average), and did not find the decision particularly difficult $(M=3.23, S D=1.68)$.

Need for further information. Our main interest pertains to participants' information need. Out of 163 participants, 34 (21\%) indicated that they did not want further information. Besides experimental condition as the independent variable, we decided to include preliminary decision certainty in our model because of its substantial correlation with the primary dependent variable, need for further information $(r=-.37, p<.001)$. We therefore conducted a logistic regression of participants' need for further information $(1=$ information requested, $0=$ no 
information requested $)$ on experimental condition $(1=$ coin, $0=$ no coin $)$ and preliminary decision certainty.

The overall logistic regression model was significant with $\chi^{2}(2)=29.39, p<.001$. Higher preliminary decision certainty resulted in a lower need for further information, $\beta=-.72$, $S E=.17$, Wald $=16.90, p<.001$, Odds Ratio $(\mathrm{OR})=.49,95 \% \mathrm{CI}_{\operatorname{Exp}(\mathrm{B})}=[.35, .69]$. In addition, we found the hypothesized negative effect of seeing a coin flip on the need for further information, $\beta=-1.12, S E=.54$, Wald $=4.27, p=.039, \mathrm{OR}=.33,95 \% \mathrm{CI}_{\operatorname{Exp}(\mathrm{B})}=[.11, .94]$. Coin participants were three times less likely to request further information than control participants. Pattern and significance levels remain the same when preliminary decision certainty is not included as a covariate, $\chi^{2}(1)=6.96, p=.008$.

To gain further insight, we conducted a second logistic regression with a more finegrained perspective on the coin participants. Specifically, we distinguished between congruent and incongruent (in relation to the preliminary decision) coin suggestions, resulting in three conditions: control, coin-congruent, coin-incongruent. Planned contrasts revealed that participants in the coin-congruent condition were 2.7 times less likely to request further information compared to the control group, but this difference did not reach statistical significance $(77.4 \%$ vs. $90.9 \% ; \beta=-.99, \mathrm{SE}=.60$, Wald $=2.74, p=.098, \mathrm{OR}=.37,95 \%$ $\left.\mathrm{CI}_{\operatorname{Exp}(\mathrm{B})}=[.12,1.20]\right)$. Participants in the coin-incongruent condition were 3.4 times less likely to request further information compared to the control group $(69.1 \%$ vs. $90.9 \% ; \beta=-1.23$, $S E=.58$, Wald $\left.=4.43, p=.035, \mathrm{OR}=.29,95 \% \mathrm{CI}_{\operatorname{Exp}(\mathrm{B})}=[.09, .92]\right)$. Again, pattern and significance levels remain the same when preliminary decision certainty is not included as a covariate, $\chi^{2}(2)=8.08, p=.018$.

Amount of information requested. The need for further information and the amount of information requested were significantly correlated, $r=.48, p<.001$. To test whether coin participants also request fewer pieces of information compared to control participants, we 
additionally conducted an ANCOVA with the number of information pieces requested as the dependent variable, experimental condition as the independent variable, and preliminary decision certainty as a covariate because of its substantial correlation with the number of information pieces $(r=-.27, p<.001)$.

As noted above, 34 participants (21\%) did not look at the additional information at all. Another 28 participants (17\%) indicated that they wanted further information but then did not select any of the snippets to read in full. For these 62 participants, the dependent variable was set to 0 ; for the other 101 participants, the range was between 1 and 10 . The covariate, preliminary decision certainty, significantly predicted the number of information pieces requested, $F(1,160)=11.07, p=.001, \eta_{\mathrm{p}}^{2}=.07$. In addition, mirroring the need for information need findings, coin participants requested fewer pieces of information $\left(M_{\text {coin }}=1.90, S E_{\text {coin }}=\right.$ $.21,95 \% \mathrm{CI}=[1.48,2.31])$ than control participants $\left(M_{\text {control }}=2.57, S E_{\text {control }}=.30,95 \% \mathrm{CI}=\right.$ $[1.98,3.16]$; both means adjusted for the covariate). The overall effect of experimental condition on the amount of information requested, however, did not reach statistical significance, $F(1,160)=3.39, p=.068, \eta_{\mathrm{p}}^{2}=.02$. See Table 1 for all descriptive statistics of Study 1 .

Table 1

Descriptive statistics for the three experimental conditions

\begin{tabular}{|c|c|c|c|}
\hline Measure & control & coin-congruent & coin-incongruent \\
\hline Need for further information (\%yes) & 90.9 & 77.4 & 69.1 \\
\hline $\begin{array}{l}\text { Number of information pieces } \\
\text { requested }^{\text {a }}\end{array}$ & $2.67(2.32)$ & $1.91(2.40)$ & $1.78(2.11)$ \\
\hline Decision changed $(\%)$ & 7.3 & 9.4 & 16.4 \\
\hline Decision certainty (1-11) & $8.95(1.64)$ & $8.91(1.75)$ & $9.18(1.52)$ \\
\hline $\begin{array}{l}\text { Change in certainty from preliminary } \\
\text { to final decision }{ }^{b}\end{array}$ & $1.15(1.13)$ & $.83(1.22)$ & $.87(1.40)$ \\
\hline Decision difficulty (1-7) & $3.13(1.50)$ & $3.36(1.74)$ & $3.20(1.80)$ \\
\hline $\begin{array}{l}\text { Mean relevance of all positive } \\
\text { information }(1-7)\end{array}$ & $3.15(1.52)$ & $3.80(1.58)$ & $3.32(1.88)$ \\
\hline
\end{tabular}


Mean relevance of all negative information (1-7)

Note. Unless otherwise noted in the measures column, the table displays means (standard deviations).

${ }^{\text {a }}$ Participants who did not want further information or only read the snippets are included with a value of 0 .

${ }^{\mathrm{b}}$ Calculated as decision certainty minus preliminary decision certainty, i.e., positive values reflect increases in decision certainty.

\section{Discussion}

Study 1 provides initial evidence that making a preliminary decision between two options and then seeing a coin flip pointing to either option reduces the need for further information compared to making a decision without a random device. This pattern is also descriptively reflected in the amount of information chosen to read. Importantly, the results cannot be explained by assuming that coin participants simply delegated the decision to chance (and therefore had no further need for information), since there is no evidence that the coin determined the decision. Descriptively, information need is even lower when the coin suggests choosing a different option than the initially preferred one.

It should be noted that the effects of the experimental manipulation were relatively small. We therefore conducted two follow-up studies to enhance confidence in our findings and test alternative explanations. First, we aimed at replicating the findings while focusing on information need as the dependent variable, leaving out the information selection step. Second, in Study 1, the coin flip manipulation had taken about 20-25 seconds longer than the respective part of the control condition. To rule out the possibility that participants in the coin conditions were more tired than those in the control condition and therefore less likely to request further information, we temporally aligned the coin and control conditions. Third, we suspected that asking participants about their preliminary decision certainty might evoke the feeling of having to defend one's view and therefore left out this variable in one of the follow-up studies.

The detailed methods and main results of the follow-up studies are described in the supplemental material. In summary, combining the evidence of all three studies yielded a 
significant overall pattern: Participants watching a coin flip had a lower need for further information compared to control participants. Temporally aligning coin and control conditions and/or not asking for preliminary decision certainty neither significantly changed this pattern nor did it significantly affect other study outcomes.

\section{Study 2}

Study 1 and the two follow-up studies demonstrate that after watching a coin flip, people are less likely to request additional information before making a decision. However, the decision scenario in Study 1 was not as ambiguous as we had expected: Most participants opted for prolonging the manager's contract. Moreover, participants were quite certain regarding their decision and did not find it particularly difficult. Given these constraints, it is remarkable that the coin flip still had an effect on participants' information need. The aim of Study 2 was to address these concerns by investigating the effects of a random device in a scenario that better simulates the indecisiveness people might have already experienced before flipping a coin. We investigated a decision in a consumer context as a domain in which it would be more realistic to flip a coin and which most people might have already encountered (in contrast to a personnel decision situation).

To this end, we presented participants with pictures of two non-branded backpacks, along with a short description about the backpacks' properties, and asked them to decide which one of the two backpacks costs more. In contrast to Study 1, this scenario represents a decision between two options (instead of a decision about keeping or changing the status quo) for which an objectively correct outcome exists.

\section{Method}

Participants and design. We recruited 260 US participants via the online platform Prolific Academic (for a review on data quality, see Peer, Brandimarte, Samat, \& Acquisti, 2017), offering a compensation of $£ 0.50$ ( $\$ 0.70$ at that time) for a median participation time of 
4 minutes. Based on our previously defined exclusion criteria, we excluded participants from our analysis who indicated low carefulness while filling out the study (i.e., a score below five on a nine-point scale, $n=1)$, who indicated their data should not be used ( $n=1)$, and/or whose native language was not English $(n=1)$. The final sample comprised 257 participants (138 male, 115 female, four undisclosed; $\left.M_{a g e}=34.77, S D_{a g e}=11.58\right)$. A sensitivity analysis with $\mathrm{G}^{*}$ Power showed that our sample size was sufficient to detect effect sizes of Cohen's $f=.18$ (.19 with three groups) or larger with $80 \%$ power.

Participants were randomly assigned to the control $\left(n_{\text {control }}=86\right)$, coin-congruent $\left(n_{\text {congr }}=87\right)$, or coin-incongruent condition $\left(n_{\text {incon }}=84\right)$.

Materials and procedure. Participants were presented with pictures and a short description of two laptop backpacks. Both were real products sold on a large international online store, the available pictures and information were similar, and no brand name was visible.

The procedure of Study 2 closely followed that of Study 1, with the following exceptions: We measured information need on a continuous scale, all participants were presented with additional information, we told participants whether their final decision was correct, and we assessed participants' reactions towards this feedback and towards the coin flip.

To obtain a continuous measure for information need, participants indicated how much further information they needed before making their final decision on a slider (ranging from 1 $=$ little additional information to $50=$ much additional information; numbers were not displayed to participants). All participants, regardless of their information need, were thereafter shown snippets from actual customer reviews for the backpacks and asked which reviews they would like to read in full (from none at all to ten, five for each backpack). Depending on participants' choice, the corresponding reviews were displayed on the following page.

After making their final decision and indicating their decision certainty, participants were informed whether they had decided correctly or not (based on the backpacks' selling price 
on the retailer's website) and were asked about their satisfaction or disappointment with their decision (both on a Likert-scale ranging from $1=$ not at all/indifferent to $7=$ very $m u c h$ ). Coin participants additionally answered three questions related to their thoughts and feelings regarding the outcome of the coin flip, namely whether the coin outcome had endorsed their preliminary decision, whether it had caused them to doubt their preliminary decision, and whether they would have liked to flip the coin a second time (all on a Likert-scale ranging from $1=$ not at all to $7=$ very much).

\section{Results}

In this study, $46.3 \%$ of participants opted for one option and $53.7 \%$ for the other, and they were less certain regarding their decision compared to participants in our previous studies $(M=7.17, S D=1.92$ on a 11 -point scale, i.e. around $60 \%$ certain $)$.

Confirmatory analyses: Information search. To test the hypothesis that coin participants have a lower need for further information compared to control participants, we conducted an ANCOVA with the need for further information as the dependent variable, experimental condition as the independent variable, and preliminary decision certainty as a covariate (given its significant correlation with the dependent variable, $r=-.15, p=.010$ ). Preliminary decision certainty significantly predicted a lower information need, $F(1,254)=$ $5.23, p=.023, \eta_{p}^{2}=.02$. Importantly, there was a significant overall effect of experimental condition on information need, $F(1,254)=5.23, p=.023, \eta_{\mathrm{p}}{ }^{2}=.02$. Pattern and significance levels remain the same when preliminary decision certainty is not included as a covariate, $F(1$, $255)=5.53, p=.019, \eta_{\mathrm{p}}^{2}=.021$.

To gain further insights, we conducted an additional ANCOVA with all three experimental groups. The overall effect of condition remained significant, $F(2,253)=3.15, p$ $=.044, \eta_{\mathrm{p}}^{2}=.02$, and planned contrast analyses (see Table 2) revealed that participants in the coin-congruent (compared to the control) condition had a significantly lower information need. Participants in the coin-incongruent (compared to the control) condition had a lower 
information need, but this difference did not reach statistical significance. Again, the pattern and significance levels remain the same when preliminary decision certainty is not included as a covariate, $F(2,254)=3.17, p=.044, \eta_{\mathrm{p}}^{2}=.024$

Table 2

Information need for each of the three experimental groups

\begin{tabular}{lcccc}
\hline \multicolumn{1}{c}{ Condition } & $\begin{array}{c}\text { Adjusted mean } \\
{[95 \% \mathrm{CI}]}\end{array}$ & $S E$ & $\begin{array}{c}\text { Mean difference to } \\
\text { control group [95\% CI] }\end{array}$ & $p$ \\
\hline Control & $23.18[20.27,26.08]$ & 1.47 & & \\
Coin-congruent & $17.98[15.09,20.87]$ & 1.46 & $5.20[1.11,9.29]$ & .013 \\
Coin-incongruent & $20.15[17.21,23.09]$ & 1.49 & $3.03[-1.11,7.16]$ & .151 \\
\hline
\end{tabular}

Note. Values could range from $1=$ little additional information to $50=$ much additional information.

Mirroring the analyses in Study 1, we also tested whether coin participants would request fewer pieces of information to read than control participants. Information need and the amount of information were significantly correlated $(r=.31, p<.01)$. We conducted an ANCOVA with the amount of information requested as the dependent variable, experimental condition as the independent variable, and preliminary decision certainty as a covariate (correlation with the amount of information: $r=-.13, p<.05$ ). Higher preliminary decision certainty predicted a lower amount of information, $F(1,254)=4.47, p=.036, \eta_{\mathrm{p}}^{2}=.02$. More importantly, participants in the coin conditions requested fewer pieces of information $\left(M_{\text {coin }}=\right.$ $\left.3.29, S E_{\text {coin }}=.20,95 \% \mathrm{CI}=[2.90,3.68]\right)$ than participants in the control condition $\left(M_{\text {control }}=\right.$ $3.75, S E_{\text {control }}=.28,95 \% \mathrm{CI}=[3.20,4.30]$; both means adjusted for the covariate), but the overall effect of experimental condition did not reach statistical significance, $F(1,254)=1.84$, $p=.177, \eta_{\mathrm{p}}^{2}=.01$. See Table 3 for all descriptive statistics.

Table 3

Descriptive statistics for the three experimental conditions

\begin{tabular}{cccc}
\hline Measure control coin-congruent & coin-incongruent \\
\hline
\end{tabular}




\begin{tabular}{|c|c|c|c|}
\hline Need for further information (1-50) & $23.28(13.92)$ & $18.06(13.60)$ & $19.96(13.84)$ \\
\hline $\begin{array}{l}\text { Number of information pieces } \\
\text { requested }\end{array}$ & $3.77(2.50)$ & $3.31(2.67)$ & $3.25(2.61)$ \\
\hline Decision changed $(\%)$ & 23.3 & 6.9 & 23.8 \\
\hline $\begin{array}{l}\text { Decision certainty } \\
(1-11)\end{array}$ & $7.40(1.94)$ & $7.52(1.93)$ & $7.45(2.07)$ \\
\hline $\begin{array}{l}\text { Change in certainty from } \\
\text { preliminary to final decision }\end{array}$ & $.33(1.43)$ & $.43(1.47)$ & $.11(1.37)$ \\
\hline $\begin{array}{l}\text { Satisfaction with being correct } \\
(1-7)\end{array}$ & $5.88(1.33)$ & $5.72(1.53)$ & $5.91(1.60)$ \\
\hline $\begin{array}{l}\text { Disappointment with being } \\
\text { incorrect }(1-7)\end{array}$ & $3.30(1.92)$ & $3.44(2.05)$ & $2.85(1.81)$ \\
\hline \multicolumn{4}{|l|}{ Reactions to coin flip (1-7) } \\
\hline Feeling validated & & $2.90(2.36)$ & $1.69(1.45)$ \\
\hline Doubting decision & & $1.47(1.29)$ & $1.85(1.56)$ \\
\hline Wish for repetition & & $1.63(1.45)$ & $1.51(1.21)$ \\
\hline
\end{tabular}

Note. Unless otherwise noted in the measures column, the table displays means (standard deviations).

${ }^{\text {a }}$ Calculated as decision certainty minus preliminary decision certainty, i.e., positive values reflect increased certainty.

\section{Exploratory analyses: Decision change, reactions to coin flip, and reactions to}

decision feedback. When looking at the descriptive data in Table 3, one finding appears noteworthy in addition to our main analyses: the percentage of participants that changed their decision throughout the study varied considerably as a function of condition. A post-hoc logistic regression $(1=$ same decision, $0=$ different decision $)$ revealed that participants in the coincongruent condition were significantly less likely to change their decision compared to both the control group, $\beta=-1.41, S E=.49, \mathrm{Wald}=8.13, p=.004, \mathrm{OR}=.24,95 \% \mathrm{CI} \operatorname{Exp}(\mathrm{B})=[.09, .64]$, and the coin-incongruent group, $\beta=-1.44, S E=.50$, Wald $=8.47, p=.004, \mathrm{OR}=.24,95 \%$ $\mathrm{CI} \operatorname{Exp}(\mathrm{B})=[.09, .63]$.

We had also assessed reactions to the coin flip, namely feeling validated, doubting the decision, or wishing to repeat the coin flip. A post-hoc MANOVA using Pillai's trace revealed a significant effect of coin condition on reactions to the coin flip, $V=0.16, F(3,167)=10.78$, 
$p<.001, \eta_{\mathrm{p}}^{2}=.16$. Separate univariate ANOVAs showed that participants in the coinincongruent condition felt significantly less validated by the coin regarding their preliminary decision, $p<.001, \eta_{\mathrm{p}}{ }^{2}=.09$. There were no significant differences regarding the other two dependent variables, $p=.089, \eta_{\mathrm{p}}{ }^{2}=.02$, for doubt and, $p=.557, \eta_{\mathrm{p}}{ }^{2}=.00$, for wishing to repeat the coin flip.

We also gave participants feedback on whether or not they had decided correctly regarding which backpack costs more and asked how satisfied or disappointed they were. There was no significant effect when comparing coin and control conditions regarding satisfaction or disappointment, $p s>.361$.

\section{Discussion}

Study 2 tested the hypothesis that a random decision device reduces information search in a different decision context, with a different decision task, and with a different participant sample than Study 1. Conceptually replicating the results of Study 1, seeing a coin flip recommending one option significantly lowered information need before making a final decision compared to making the same decision without a coin flip. This pattern is also reflected in the amount of information participants wanted to read.

In addition to information search, the coin flip influenced the likelihood of sticking to one's initial preference: Participants who saw a coin flip in line with their preliminary decision switched to the other option less often at the end of the study. We interpret this exploratory finding as initial evidence that a random device recommending an option in line with one's preference can serve as a confirming cue.

We also assessed participants' reactions towards their final decision. Satisfaction or disappointment upon learning that the decision was correct or wrong, respectively, were unaffected by the coin flip. We infer that participants felt responsible for their decisions instead of transferring responsibility to the coin, a finding which is in line with previous research (Steffel et al., 2016) and demonstrates that a random device is different than delegating a 
decision to others: Letting chance decide determines an outcome and therefore takes the burden of choosing, but only delegating the decision to someone else can additionally take the burden of responsibility associated with the decision outcome (Steffel et al., 2016).

\section{Study 3}

The studies so far demonstrated that information need is significantly lowered after receiving a random suggestion, be it a decision between changing versus maintaining a status quo without an objectively correct solution, or a decision between two options for which an objectively correct solution exists. With Study 3, we aimed at replicating our findings for a real and consequential decision between two options without an objectively correct solution while also increasing ecological validity and generalizability.

With these goals in mind, we turned to a donation decision and asked participants to decide which one of two medical charities should receive a monetary donation. Requests to donate and how much to donate represent moral conflicts that a substantial number of people prefer to resolve by a coin flip when given the chance to do so (Lin \& Reich, 2018). Moreover, prior research suggests that donation decisions matter to people, even when the money involved is not their own. In particular, people are willing to cheat (i.e., to engage in an immoral behavior) so that a deserving charity is allocated more money, and so that a deserving instead of an undeserving charity receives money (Rixom \& Mishra, 2014). Against this background, there is good reason to assume that participants perceive a donation decision as more important and relevant than decisions between backpacks or a decision within a fictitious employment scenario. By implementing a donation decision with actual money, Study 3 thus addresses the potential caveat of non-consequentiality inherent to Studies 1 and 2.

A second potential caveat of Studies 1 and 2 is the restriction to two specific options in each study. To address this, Study 3 contained six options, thereby reducing the likelihood that unknown idiosyncratic properties of choice options play a key role. 
Finally, we designed Study 3 so that three conceptual concerns can be addressed. In short, it has been suggested that our findings may be attributable to pragmatic inference (i.e., coin participants might have perceived the use of a coin flip as a signal that the decision is unimportant and thereby feel that additional information is not warranted), relinquishment of control (i.e., coin participants might have perceived that the decision is rather determined by the coin than by themselves), and suspicion (i.e., coin participants might have thought that the coin is rigged or biased).

\section{Method}

Participants and design. We recruited 279 US participants via Prolific Academic ${ }^{1}$, offering a compensation of $£ 0.60$ ( $\$ 0.77$ at that time) for a median participation time of 6 minutes. Based on our previously defined exclusion criteria, we excluded participants from our analysis who indicated low carefulness while filling out the study (i.e., a score below five on a nine-point scale, $n=1)$ and who indicated their data should not be used $(n=4)$. In addition, one participant had indicated that the survey crashed mid-way and another participant commented "this is all fake" as a reason for making his/her donation decision, so we excluded these two before analyzing the data. The final sample comprised 272 participants (123 male, 144 female, four undisclosed; $\left.M_{a g e}=32.48, S D_{a g e}=11.99\right)$. A sensitivity analysis with G*Power showed that our sample size was sufficient to detect effect sizes of Cohen's $d=.32(f=.19$ with three groups) or larger with $80 \%$ power.

Participants were randomly assigned to the control $\left(n_{\text {control }}=90\right)$ and two coin conditions $\left(n_{\text {heads }}=93, n_{\text {tails }}=89\right)$.

Materials and procedure. We informed participants that we are interested in how people make donation decisions, in particular with regard to medical charities. We then told them that they will receive a compensation of $£ 0.60$ for the study and that they can additionally

\footnotetext{
${ }^{1}$ We had aimed for 260 participants, as in Study 2, but ended up with a larger sample due to a technical glitch on the Prolific Academic website.
} 
choose a charity that will receive $£ 0.10$. It was stressed that these additional $£ 0.10$ will be donated to the charity and will not be part of the participant compensation, so that they will always receive $£ 0.60$. Given the findings of Rixom and Mishra (2014) reviewed above, there is good reason to assume that participants care about this donation decision even if they do not donate their own money. Next, we provided participants with a list of six US-based medical charities which had been preselected by the first author from hmr.org: Aplastic Anemia \& MDS International Foundation, Charcot-Marie-Tooth Association, Mesothelioma Applied Research Foundation, Pachyonychia Congenita Project, Sjogren's Syndrome Foundation, and Williams Syndrome Foundation. For each charity, participants were asked to indicate whether they know the charity, whether they know the disease associated with it, or whether they know neither. Only if participants ticked the last option for at least two charities (i.e., at least two charities and the respective diseases were unknown), they could continue the study (true for all but five participants in the initial sample). We had selected rather unknown diseases and charities and implemented the screening procedure described above to increase the likelihood that participants experience the need to gather further information.

Next, we informed participants that we randomly selected two of the unknown charities for the remainder of the study, and asked for a preliminary donation decision between those two charities based on the charity's name, its foundation year, and the city in which it is based. Again, we decided to provide minimal information so that enough room is left for a potential need to gather further information. Participants in the coin conditions were then introduced to the coin flip procedure. In contrast to the previous studies, participants first saw a trial coin flip and could subsequently test the coin as many times as they wanted. After completing the trial(s), the actual coin flip was run and randomly suggested one of the two charities.

On the next page, we asked all participants how much more information they need about the two charities before they can make their donation decision. To this end, participants saw two separate slider scales, one for each charity (ranging from $1=$ no further information to 10 
$=$ much more information). All participants, regardless of their information needs, were thereafter provided with the links to the charities' websites in case they wanted to obtain more information. Before making their final decision which charity they would like to donate for, we asked participants to write down at least one and up to five reasons for their decision.

Finally, we asked all participants how autonomously they had made their decision (on a Likert-scale ranging from 1 = not at all autonomously to 7 = very autonomously). In addition, we asked coin participants to think back to the moment when they first interacted with the coin and to answer the following two questions: "If this same coin would now be flipped 100 times, how many times do you think it would land on heads?" and "If this same coin would now be flipped 100 times, how many times do you think it would land on tails?" (order counterbalanced). If participants indicated anything else than " 50 " for either or both, we asked them on a separate page whether they thought that the coin was biased (yes/no). Lastly, we asked all coin participants to which extent they agree with the following statement: "Flipping a coin before making a decision is a signal that it is an unimportant decision" (on a Likert-scale ranging from $1=I$ strongly disagree to $7=I$ strongly agree and the midpoint 4 labeled with $I$ do not have an opinion on that).

The presentation order (first/second) of the two charities was randomly determined throughout the study (i.e., for all presentations, scales, decisions).

\section{Results}

Information search. To test the hypothesis that participants in the two coin conditions have a lower need for further information, we conducted a one-sided t-test with the need for further information as the dependent variable. Because the need for further information did not differ between the two charities $(M=7.58, S D=2.82$ vs. $M=7.65, S D=2.80)$, we summed up the two scores, resulting in a total information need score (overall $M=15.23, S D=5.40$ ). As hypothesized, coin participants had a significantly lower information need $(M=14.57, S D=$ 
5.64) than control participants $(M=16.58, S D=4.62), t(212)=3.14,95 \% \mathrm{CI}=[.75,3.28], p=$ $.001, d=.39)$.

Participants' preliminary decision was evenly split between the two charities (55.5\% vs. 44.5\%). This allowed us to further divide the coin participants into coin-congruent and coinincongruent participants with similar $n$ (90 and 92) and to thus run an ANOVA with the three groups control, coin-congruent, and coin-incongruent. The ANOVA showed a significant effect of condition $\left(F(2,269)=4.67, p=.010, \eta_{\mathrm{p}}^{2}=.03\right)$ and Games-Howell pairwise comparisons showed that information need was significantly lower for coin-congruent $(M=14.22, S D=$ 6.08) compared to control participants $(M=16.58, S D=4.62 ; p=.011)$ and lower for coinincongruent $(M=14.90, S D=5.18)$ compared to control participants $(p=.058)$, but that the two coin conditions did not differ $(p=.696)$.

As in Studies 1 and 2, we examined the amount of information participants took into account after indicating their information need and before making a final decision. Different from Studies 1 and 2, we here operationalized information search as the total time spent on the two charities' websites. Information search was significantly correlated with information need $(r=.37, p=.010)$. Mirroring previous results, participants in the coin conditions spent less time on the websites (in seconds: $M=80, S D=67)$ than control participants $(M=96, S D=94$; $t(135)=1.49,95 \% \mathrm{CI}=[-5.44,38.43], p=.069($ one-tailed $), d=.20)$. Note that the high levels of variability are at least partly due to the fact that the web application we used to collect data is not engineered to reliably measure reaction times.

Decision and reasons for decision. Most participants did not deviate from their preliminary decision: $72.8 \%$ chose the same charity at the end of the study, and there was no influence of experimental condition on this proportion $\left(\chi^{2}(1)=1.04, p=.309\right)$. Furthermore, perceived autonomy regarding the decision did not differ between coin $(M=5.30, S D=1.73)$ and control participants $(M=5.51, S D=1.68 ; t(270)=.945,95 \% \mathrm{CI}=[-.23, .64], p=.346)$. Participants' mean number of reasons for their decisions was $1.85(S D=1.10)$. Mirroring the 
results regarding information need and search, participants in the coin conditions wrote down fewer reasons $(M=1.77, S D=1.07)$ than control participants $(M=2.01, S D=1.15 ; t(270)=$ $1.71,95 \% \mathrm{CI}=[-.37, .52], p=.088$ (two-tailed), $d=.22)$.

Additional analyses within the coin conditions: perceptions of the coin. After being introduced to the trial coin flip, none of the 182 participants in the coin conditions wanted to test the coin flip again. When asked at the end of the study how many times they think the coin would land on heads and tails if flipped again, 34 (19\% of all participants in the coin condition) indicated something else than " 50 " for one or both questions. We asked those 34 participants on a separate page whether they thought that the coin was biased, which 13 participants affirmed. This represents $4.8 \%$ of the whole sample ${ }^{2}$.

When asked whether using a coin flip for a decision signals that it is an unimportant decision, participants' mean response was $4.26(S D=1.71$, on a Likert-scale ranging from 1 to 7 with the midpoint of 4 labeled "I do not have an opinion on that"), the median was 4 , and the mode was 3 . There was no association between this variable and information need $(r=-.06, p$ $=.459)$ or time spent on the websites $(r=-.11, p=.883)$.

\section{Discussion}

Study 3 tested the hypothesis that a random decision device reduces information search for a real decision for which no objectively correct solution exists. Conceptually replicating the results of our previous studies, participants reported a significantly lower information need before making a final decision when they saw a coin flip recommending one option compared to participants who made this decision without a coin flip. This pattern is also (nonsignificantly) reflected in the time participants spent to gather additional information as well as the number of reasons participants indicate for their decision. We thus also find the

\footnotetext{
${ }^{2}$ Excluding these 13 participants does not change our pattern of results or significance levels; the same is true if we further exclude those 21 participants who indicated something other than 50 for the two randomness-frequency questions (statistically, all values are possible and therefore correct answers), but without explicitly expressing doubts about the coin.
} 
hypothesized effect of a coin flip on information search when the decision at hand is consequential (with actual money being donated to charities) and when it appears to matter for participants, given that they voluntarily spent about 1.4 minutes on charity websites although they received a fixed amount of money for study participation.

In addition, we tested and refuted three alternative accounts, all associating the decrease in information need with specific conceptual aspects of using a random device. First, results suggest that coin participants did not view the decision as less important simply because a coin was involved, refuting pragmatic inference as a potential alternative explanation. Second, results show that coin and control participants felt similarly in control of their decision and made it autonomously, suggesting that coin participants' lowered information need does not result from a relinquishment of control. Finally, only very few coin participants were questioning that the coin is fair, and the pattern of results did not depend on their answers, thus ruling out suspicion about the coin as the reason to search less.

Although participants were asked to make their preliminary decision only on the basis of the charity's name, the foundation year, and the charity's location, the majority of participants did not change their decision throughout the study. This suggests that participants had made up their mind early on and that the coin flip, as in the other studies, did not influence the decision outcome but primarily speeded up the decision process. Perhaps this is because information provided on charity websites is generally in favor of donating to the charity (and not against), so that visiting the websites does rather not sway participants away from their initially expressed preference.

\section{General Discussion}

The present research investigated whether a random device, namely a coin flip, can influence information search for an upcoming decision. Across five studies (total $N=997$ ), we provide evidence that the need for further information is reduced after watching a coin flip 
suggesting one option over another: People are less likely to request further information (Studies 1, 1b, 1c) and indicate a lower need for more information before making a final decision (Studies 2 and 3). We show this for situations involving a decision about whether to keep or change the status quo without an objectively correct solution (Studies 1, 1b, 1c), and for situations involving a decision between two options with (Study 2) and without an objectively correct solution (Study 3). Moreover, results were obtained with participants recruited from two different populations (Germans in Studies 1, 1b, 1c; US-Americans in Studies 2 and 3) and for both hypothetical and real decisions.

Mirroring the results obtained for information need, coin participants compared to control participants always descriptively consulted less information, but this pattern was never significant. This partial dissociation between information need and information amount is consistent with recent research showing that people overestimate how much information they and others take into account to make up their mind (Klein \& O'Brien, 2018). In line with this, we observed that some participants in Study 1 did not request to read any of the snippets in full, although they had indicated needing more information, suggesting that their need was satisfied by the short information snippets alone. We assume that this also played a role in Study 2 , where information need significantly differed between groups but did not fully translate into the subsequently checked number of information pieces to read, likely because the information snippets might have already been sufficient for participants. In Study 3, we provided participants with the websites of unknown charities and analyzed how much time they spent on the respective websites as a proxy for actual information search. However, the benefit of ecological validity by providing naturalistic sources comes at the expense of experimental control. Factors such as speed of participants' Internet connection, reading speed, server response latencies, and differences in website content and usability add noise. It might prove beneficial in future research to control for these factors and to obtain more fine-grained measures of information search, as well as to control for individual differences on the person- 
level that impact information search (e.g., need for structure or fear of invalidity; Mayseless \& Kruglanski, 1987).

Throughout our studies, coin participants were not more often swayed away from their initial preference than control participants, but needed less information to make their final decision. Our results are therefore in line with research showing that once a first impression is made, it is often resistant to change, even if additional information might warrant to do so (e.g., Gawronski, Rydell, Vervliet, \& De Houwer, 2010; Yu, Saleem, \& Gonzalez, 2014). This is also consistent with the notion of the mere measurement effect (e.g., Fitzsimons \& Williams, 2000; Levav \& Fitzsimons, 2006), which holds that asking people for their intention to engage in a particular behavior makes it more likely that they subsequently engage in this behavior. If one equates our preliminary decision with asking for an intention, this intention then stood a higher chance of being carried through. It should be acknowledged that none of the information pieces we presented to participants was designed to fundamentally overpower all other information. It would be interesting to test in future research whether differences between experimental conditions arise when some piece of information clearly suggests that one should deviate from the preliminary decision.

\section{Theoretical and Practical Contributions}

Our results conceptually align with research showing that specific physical acts associated with the concept of closure (e.g., closing or covering something) can trigger choice closure (Gu et al., 2013). Because a coin flip is normally used to determine an outcome, it might activate the concept of having made a final decision. Similarly, it might signal a transition from deliberation to implementation (Beckmann \& Gollwitzer, 1987; Heckhausen \& Gollwitzer, 1987). Both of these explanations relate to the notion that by flipping a coin, one moves closer to the decision and thereby needs less information, which is also in line with a Construal Level Theory perspective (Halamish \& Liberman, 2017). 
Beyond this, we move towards understanding a phenomenon for which experimental studies are lacking, namely that some people are unable to decide but suddenly realize what they prefer after leaving the decision up to chance. Given that a coin flip reduces information need when people have an explicit preference, it might similarly reduce information need when this preference is not yet explicit but will be so in the future. As Galdi, Gawronski, Arcuri, and Friese (2012) point out, "people who are undecided about two available options may sometimes have a gut feeling that one of them may be better than the other" (p. 560). A coin flip might empower this gut feeling by promoting an implemental mindset and signaling choice closure.

Furthermore, we bridge the gap in the literature between making decisions by oneself and delegating decisions to others. So far, the use of random devices has been subsumed under choice avoidance (Dwenger, Kubler, \& Weizsäcker, 2013; Steffel et al., 2016) or as a consequence of decision aversion (Beattie et al., 1994). We show that a device normally used to bypass decision-making has the potential to let people settle for a final decision without (endlessly) searching for more information.

From an applied perspective, our findings suggest ways in which the tendency to delay decisions by gathering further information could be reduced. We do not suggest that people should make decisions without taking available information into account or without looking for additional information, but as outlined in our introduction, there are situations in which abundant information can have detrimental effects. In his model of indecisiveness, Rassin (2006) names information search as a delaying behavior when people are undecided. Likewise, Schrift and Parker (2014) describe searching for information as a "no-choice option", along with procrastinating and deferring judgments. Given that people take less information into account than they think to come to conclusions (Klein \& O'Brien, 2018), the coin flip may simply speed up what would happen anyway.

Although a normative perspective is not the focus of this paper, the question when to stop looking for information before making a decision is a truly intriguing one. Information is 
important and, other things being equal, more information is better. Yet, oftentimes, other things are not equal: Gathering information has a price as it requires time and cognitive resources. Hence, there is likely no normative answer on when to stop the search for additional information, especially because this stopping decision is highly dependent on various decision dimensions such as importance, urgency, normativity, and the availability of pro and con arguments.

The present results suggest that using a random device has the potential to overcome sidestepping a decision by lowering the felt need for further information. This is particularly intriguing in the domain of prosocial behavior: If people have a hard time deciding whether and to which extent they should act in a prosocial way, providing them with a random suggestion might help them deciding, instead of delaying the decision (thereby potentially missing out on opportunities to help others) or avoiding the decision altogether. This appears all the more promising given that individuals are readily willing to rely on random devices when making prosocial decisions (Lin \& Reich, 2018).

\section{Conclusion}

People usually gather information before making decisions. Information search, however, can lead to delaying decisions, as more information does not always help with a decision. We provide evidence that consulting a random device, namely a coin flip, can reduce the need for further information, thereby suggesting a way to overcome decision blocks.

\section{Open Practices}

Data, analyses, and materials for all studies are available at: https://bit.ly/2ljvoKP. 


\section{References}

Batson, C. D., Kobrynowicz, D., Dinnerstein, J. L., Kampf, H. C., \& Wilson, A. D. (1997). In a very different voice: Unmasking moral hypocrisy. Journal of Personality and Social Psychology, 72, 1335-1348. http://dx.doi.org/10.1037/0022-3514.72.6.1335

Beattie, J., Baron, J., Hershey, J. C., \& Spranca, M. D. (1994). Psychological determinants of decision attitude. Journal of Behavioral Decision Making, 7, 129-144. https://doi.org/10.1002/bdm.3960070206

Beckmann, J., \& Gollwitzer, P. M. (1987). Deliberative versus implemental states of mind: The issue of impartiality in predecisional and postdecisional information processing. Social Cognition, 5, 259-279. https://doi.org/10.1521/soco.1987.5.3.259

Bolton, G. E., Brandts, J., \& Ockenfels, A. (2005). Fair procedures: Evidence from games involving lotteries. Economic Journal, 115, 1054-1076. https://doi.org/10.1111/j.14680297.2005.01032.x

Botti, S., \& Iyengar, S. S. (2004). The psychological pleasure and pain of choosing: When people prefer choosing at the cost of subsequent outcome satisfaction. Journal of Personality and Social Psychology, 87, 312-326. https://doi.org/10.1037/00223514.87.3.312

Botti, S., \& McGill, A. L. (2006). When choosing is not deciding: The effect of perceived responsibility on satisfaction. Journal of Consumer Research, 33, 211-219. https://doi.org/10.1086/506302

Carpenter, S. M., Yates, J. F., Preston, S. D., \& Chen, L. (2016). Regulating emotions during difficult multiattribute decision making: The role of pre-decisional coherence shifting. PLoS ONE, 11(3), 1-21. https://doi.org/10.1371/journal.pone.0150873

Dwenger, N., Kubler, D., \& Weizsäcker, G. (2013). Flipping a coin: Theory and evidence (Working Paper). Retrieved from SSRN: https://ssrn.com/abstract=2353282

Eidelman, S., \& Crandall, C. S. (2012). Bias in favor of the status quo. Social and Personality 
Psychology Compass, 3, 270-281. Retrieved from http://www.academia.edu/1974568/Bias_in_Favor_of_the_Status_Quo

Eliaz, K., \& Rubinstein, A. (2014). On the fairness of random procedures. Economics Letters, 123, 168-170. https://doi.org/10.1016/j.econlet.2014.01.042

Faul, F., Erdfelder, E., Lang, A. G., \& Buchner, A. (2007). G*power 3: A flexible statistical power analysis program for the social, behavioral, and biomedical sciences. Behavior Research Methods, 39, 175-191. https://doi.org/10.3758/BF03193146

Fischer, P., Fischer, J., Weisweiler, S., \& Frey, D. (2010). Selective exposure to information: How different modes of decision making affect subsequent confirmatory information processing. The British Psychological Society, 49, 871-881. https://doi.org/10.1348/014466610X499668

Fischer, P., Lea, S., Kastenmüller, A., Greitemeyer, T., Fischer, J., \& Frey, D. (2011). The process of selective exposure: Why confirmatory information search weakens over time. Organizational Behavior and Human Decision Processes, 114, 37-48. https://doi.org/10.1016/j.obhdp.2010.09.001

Fitzsimons, G. J., \& Williams, P. (2000). Asking questions can change choice behavior: Does it do so automatically or effortfully? Journal of Experimental Psychology: Applied, 6, 195-206. https://doi.org/10.1037/1076-898X.6.3.195

Fukukura, J., Ferguson, M. J., \& Fujita, K. (2013). Psychological distance can improve decision making under information overload via gist memory. Journal of Experimental Psychology: General, 142, 658-665. https://doi.org/10.1037/a0030730

Galdi, S., Gawronski, B., Arcuri, L., \& Friese, M. (2012). Selective exposure in decided and undecided individuals. Personality and Social Psychology Bulletin, 38, 559-569. https://doi.org/10.1177/0146167211435981

Gawronski, B., Rydell, R. J., Vervliet, B., \& De Houwer, J. (2010). Generalization versus contextualization in automatic evaluation. Journal of Experimental Psychology: General, 
139, 683-701. https://doi.org/10.1037/a0020315

Gino, F., Norton, M. I., \& Weber, R. A. (2016). Motivated Bayesians: Feeling moral while acting egoistically. Journal of Economic Perspectives, 30, 189-212. https://doi.org/10.1257/jep.30.3.189

Gordon-Hecker, T., Rosensaft-Eshel, D., Pittarello, A., Shalvi, S., \& Bereby-Meyer, Y. (2017). Not taking responsibility: Equity trumps efficiency in allocation decisions. Journal of Experimental Psychology: General, 146, 771-775. https://doi.org/10.1037/xge0000273

Gu, Y., Botti, S., \& Faro, D. (2013). Turning the page: The impact of choice closure on satisfaction. Journal of Consumer Research, 40, 268-283. https://doi.org/10.1086/670252

Halamish, V., \& Liberman, N. (2017). How much information to sample before making a decision? It's a matter of psychological distance. Journal of Experimental Social Psychology, 71, 111-116. https://doi.org/10.1016/j.jesp.2017.03.004

Heckhausen, H., \& Gollwitzer, P. M. (1987). Thought contents and cognitive functioning in motivational versus volitional states of mind. Motivation and Emotion, 11, 101-120. http://dx.doi.org/10.1007/BF00992338

Kelley, H. H. (1971). Attribution in social interaction. New York: General Learning Press.

Keren, G., \& Teigen, K. H. (2010). Decisions by coin toss: Inappropriate but fair. Judgment and Decision Making, 5(2), 83-101.

Klein, N., \& O'Brien, E. (2018). People use less information than they think to make up their minds. Proceedings of the National Academy of Sciences, 115, 13222-13227. https://doi.org/10.1073/pnas.1805327115

Leonhardt, J. M., Keller, L. R., \& Pechmann, C. (2011). Avoiding the risk of responsibility by seeking uncertainty: Responsibility aversion and preference for indirect agency when choosing for others. Journal of Consumer Psychology, 21, 405-413. 
https://doi.org/10.1016/j.jcps.2011.01.001

Leotti, L. A., \& Delgado, M. R. (2011). The inherent reward of choice. Psychological Science, 22, 1310-1318. https://doi.org/10.1177/0956797611417005

Leotti, L. A., Iyengar, S. S., \& Ochsner, K. N. (2011). Born to choose: The origins and value of the need for control. Trends in Cognitive Sciences, 14, 457-463. https://doi.org/10.1016/j.tics.2010.08.001

Levav, J., \& Fitzsimons, G. J. (2006). When questions change behavior: The role of ease of representation. Psychological Science, 17, 207-213. https://doi.org/10.1111/j.14679280.2006.01687.x

Levitt, S. D. (2016). Heads or tails: The impact of a coin toss on major life decisions and subsequent happiness (NBER Working Paper No. 22487). Retrieved from National Bureau of Economic Research website: http://www.nber.org/papers/w22487

Liberman, N., \& Trope, Y. (2008). The psychology of transcending the here and now. Science, 322, 1201-1206. https://doi.org/10.1126/science.1161958

Lin, S. C., \& Reich, T. (2018). To give or not to give? Choosing chance under moral conflict. Journal of Consumer Psychology, 28, 211-233. https://doi.org/10.1002/jcpy.1008

Lutz, J. (2016). The validity of crowdsourcing data in studying anger and aggressive behavior: A comparison of online and laboratory data. Social Psychology, 47, 38-51. https://doi.org/10.1027/1864-9335/a000256

Mayseless, O., \& Kruglanski, A. W. (1987). Accuracy of estimates in the social comparison of abilities. Journal of Experimental Social Psychology, 23, 217-229. http://dx.doi.org/10.1016/0022-1031(87)90033-3

Mojzisch, A., Schulz-Hardt, S., Kerschreiter, R., \& Frey, D. (2008). Combined effects of knowledge about others' opinions and anticipation of group discussion on confirmatory information search. Small Group Research, 39, 203-223. https://doi.org/10.1177/1046496408315983 
O’Reilly, C. A. (1980). Individuals and information overload in organizations: Is more necessarily better? Academy of Management Journal, 23, 684-696. https://doi.org/10.5465/255556

Oettingen, G. (2012). Future thought and behaviour change. European Review of Social Psychology, 23, 1-63. https://doi.org/10.1080/10463283.2011.643698

Oettingen, G., \& Schwörer, B. (2013). Mind wandering via mental contrasting as a tool for behavior change. Frontiers in Psychology, 4, 1-5. https://doi.org/10.3389/fpsyg.2013.00562

Peer, E., Brandimarte, L., Samat, S., \& Acquisti, A. (2017). Beyond the Turk: Alternative platforms for crowdsourcing behavioral research. Journal of Experimental Social Psychology, 70, 153-163. https://doi.org/10.1016/j.jesp.2017.01.006

Peters, E., Klein, W., Kaufman, A., Meilleur, L., \& Dixon, A. (2013). More is not always better: Intuitions about effective public policity can lead to unintended consequences. Social Issues and Policy Review, 7, 114-148. https://doi.org/10.1111/j.17512409.2012.01045.x

Rassin, E. (2006). A psychological theory of indecisiveness. Netherlands Journal of Psychology, 2-13. https://doi.org/10.1007/BF03061056

Redelmeier, D. A., Shafir, E., \& Aujla, P. S. (2001). The beguiling pursuit of more information. Medical Decision Making, 21, 376-381. https://doi.org/10.1177/0272989X0102100504

Richard, F. D., Bond, C. F., \& Stokes-Zoota, J. J. (2003). One hundred years of social psychology quantitatively described. Review of General Psychology, 7, 331-363. https://doi.org/10.1037/1089-2680.7.4.331

Ritov, I., \& Baron, J. (1992). Status-quo and omission biases. Journal of Risk and Uncertainty, 5, 49-61. https://doi.org/10.1007/BF00208786

Rixom, J., \& Mishra, H. (2014). Ethical ends: Effect of abstract mindsets in ethical decisions 
for the greater social good. Organizational Behavior and Human Decision Processes, 124, 110-121. https://doi.org/10.1016/j.obhdp.2014.02.001

Samuelson, W., \& Zeckhauser, R. (1998). Status quo bias in decision making. Journal of Risk and Uncertainty, 1, 7-59. https://doi.org/10.1007/BF00055564

Schmidt, J. B., \& Spreng, R. A. (1996). A proposed model of external consumer information search. Journal of the Academy of Marketing Science, 24, 246-256. https://doi.org/10.1177/0092070396243005

Schrift, R. Y., \& Parker, J. R. (2014). Staying the course: The option of doing nothing and its impact on postchoice persistence. Psychological Science, 25, 772-780. https://doi.org/10.1177/0956797613516801

Shalvi, S., Dana, J., Handgraaf, M. J. J., \& De Dreu, C. K. W. (2011). Justified ethicality: Observing desired counterfactuals modifies ethical perceptions and behavior. Organizational Behavior and Human Decision Processes, 115, 181-190. https://doi.org/10.1016/j.obhdp.2011.02.001

Simonsohn, U. (2009). Direct risk aversion. Psychological Science, 20, 686-692. https://doi.org/10.1111/j.1467-9280.2009.02349.x

Skinner, E. A. (1996). A guide to constructs of control. Journal of Personality and Social Psychology, 71, 549-570. https://doi.org/10.1007/BF00014299

Steffel, M., \& Williams, E. F. (2017). Delegating decisions: Recruiting others to make choices we might regret. Journal of Consumer Research, 44, 1015-1032. https://doi.org/10.1093/jcr/ucx080

Steffel, M., Williams, E. F., \& Perrmann-Graham, J. (2016). Passing the buck: Delegating choices to others to avoid responsibility and blame. Organizational Behavior and Human Decision Processes, 135, 32-44. https://doi.org/10.1016/j.obhdp.2016.04.006

Trope, Y., \& Liberman, N. (2010). Construal-level theory of psychological distance. Psychological Review, 117, 440-463. https://doi.org/10.1037/a0018963 
Van Harreveld, F., Rutjens, B. T., Rotteveel, M., Nordgren, L. F., \& van der Pligt, J. (2009). Ambivalence and decisional conflict as a cause of psychological discomfort: Feeling tense before jumping off the fence. Journal of Experimental Social Psychology, 45, 167173. https://doi.org/10.1016/j.jesp.2008.08.015

Von Neumann, J., \& Morgenstern, O. (1947). Theory of games and economic behavior $\left(2^{\text {nd }}\right.$ ed.). Princeton, NJ: Princeton University Press.

Woolley, K., \& Risen, J. L. (2018). Closing your eyes to follow your heart: Avoiding information to protect a strong intuitive preference. Journal of Personality and Social Psychology, 114, 230-245. https://doi.org/10.1037/pspa0000100

Yu, M., Saleem, M., \& Gonzalez, C. (2014). Developing trust: First impressions and experience. Journal of Economic Psychology, 43, 16-29.

https://doi.org/10.1016/j.joep.2014.04.004 


\section{Supplementary Material}

\section{Study 1b}

\section{Method}

Participants and design. For this study, we recruited 120 German participants via the online platform Clickworker, offering compensation of $€ 0,75$ ( $\$ 0.93$ at that time) for a median participation time of 5 minutes. We received complete datasets from 117 participants $^{3}$ and then excluded eight participants from our analysis based on previously defined exclusion criteria (participants who indicated low carefulness while filling out the study, i.e., a score below five on a nine-point scale, $n=3$; participants who indicated their data should not be used, $n=2$; participants who indicated to have already participated in a very similar study, $n=3$ ). The final sample comprised 109 participants (58 male, 49 female, two undisclosed; $M_{\text {age }}=33.71$, $\left.S D_{\text {age }}=13.00\right)$. A sensitivity analysis with $\mathrm{G}^{*}$ Power showed that our sample size was sufficient to detect effect sizes of $w=.27$ ( $w=.30$ when using $2 \mathrm{df}$ ) or larger with $80 \%$ power.

Participants were randomly assigned to the control $\left(n_{\text {control }}=38\right)$, coin-congruent $\left(n_{\text {congr }}=35\right)$, or coin-incongruent condition $\left(n_{\text {incon }}=36\right)$. The need for further information served as a binary dependent variable.

Materials and procedure. Materials and procedure were identical to Study 1 with the following exceptions: First, because there was a significant time difference of about 20-25 seconds between the coin and control groups in Study 1 (due to introducing the coin flip and showing the outcomes afterwards), we shortened the duration of the coin flip manipulation to rule out the possibility that participants were simply tired and therefore less likely to request further information. To this end, we did not explain the outcomes beforehand but directly placed them on the sides of the coin ("Yes" and "No"), shortened the animation from 10 to 6 seconds,

\footnotetext{
3 The difference of three participants between intended and actual sample size is likely due to technical properties of the panel website and lay outside of our control.
} 
and let participants look at the coin flip outcome for only 4 seconds instead of giving them unlimited time.

Second, we suspected that asking participants about their preliminary decision certainty might evoke the feeling of having to defend one's view with possibly uncontrolled side-effects. We therefore only asked for their certainty after making the final decision.

Third, because we focused on the need for further information, participants did not have to select which of the additional pieces of information they wanted to read. Instead, we displayed all 10 pieces of information on one page for the participants who had indicated that they needed further information. We consequently did not assess the relevance of each information piece either.

Lastly, at the end of the study, we asked participants whether they were in a job position involving personnel responsibilities and whether they had already participated in a similar study before, with the latter being added to our list of exclusion criteria.

\section{Results}

Because we did not measure preliminary decision certainty in this study, we conducted a $2 \times 2$ chi-square test for our main analysis with condition (coin vs. control) and the need for further information (yes vs. no). Although the resulting pattern of results is as predicted with coin participants having a lower need for further information than control participants, the association between condition and information need was not significant, $\chi^{2}(1)=0.25, p=.616$, $w=.05$.

\section{Study 1c}

\section{Method}


Participants and design. Based on the effect size obtained in Study 1, we recruited 215 German participants $\left(217\right.$ completed the survey $\left.{ }^{4}\right)$ via the online platform Clickworker, offering compensation of $€ 0,75$ ( $\$ 0.93$ at that time) for a median participation time of 5 minutes. Based on our previously defined exclusion criteria, we excluded 18 participants from our analysis (participants who indicated low carefulness while filling out the study, i.e., a score below five on a nine-point scale, $n=3$; participants who indicated their data should not be used, $n=7$; participants who indicated to already have participated in a very similar study, $n=9$ ). The final sample comprised 199 participants (99 male, 99 female, one undisclosed; $M_{\text {age }}=35.83, S D_{\text {age }}$ $=12.10$ ). A sensitivity analysis with $G^{*}$ Power showed that our sample size was sufficient to detect effect sizes of $w=.20(w=.22$ when using $2 \mathrm{df})$ or larger with $80 \%$ power.

Participants were randomly assigned to the control $\left(n_{\text {control }}=68\right)$, coin-congruent $\left(n_{\text {congr }}=64\right)$, or coin-incongruent condition $\left(n_{\text {incon }}=67\right)$. The need for further information served as a binary dependent variable.

Materials and procedure. Materials and procedure were identical to Study $1 \mathrm{~b}$ with the following exceptions: First, because there still was a slight time difference between the coin and control groups in Study $1 \mathrm{~b}$, we additionally extended the duration of the hourglass animation from 10 to 15 seconds, thereby employing an even stronger test of the possibility that the reduced need for information in the coin conditions might be a function of the time difference.

Second, because leaving out the preliminary decision certainty measure in the previous study did not alter the results, we again included this measure to be able to control for its effects.

\section{Results}

We conducted a $2 \times 2$ chi-square test for our main analysis with condition (coin vs. control) and the need for further information (yes vs. no). Although the resulting pattern of

\footnotetext{
${ }^{4}$ Due to an initial miscalculation of the effect size from Study 1, we had to recruit participants in two waves $\left(n_{1}=120\right.$ and $\left.n_{2}=95\right)$. The difference of two participants between intended and actual sample size is likely due to technical properties of the panel website and lay outside of our control.
} 
results is as predicted with coin participants having a lower need for further information than control participants, the association between condition and information need was not significant, $\chi^{2}(1)=2.42, p=.120, w=.11$.

\section{Combined Results of Studies 1, 1b, and 1c}

To obtain a meta-analytic estimate for our studies, we use Fisher's method (1925) of combining p-values from multiple independent studies testing the same hypothesis. With the three $\mathrm{p}$-values from our studies $(p=.039$ in Study $1, p=.616$ in Study $1 \mathrm{~b}$, and $p=.120$ in Study 1c), Fisher's method gives a test statistic of $\chi^{2}=14.86$ with 6 degrees of freedom and a combined $p=.021$.

For an overview, the descriptive statistics of Studies 1, 1b, and 1c are displayed in Table 4. More detailed analyses for Studies $1 \mathrm{~b}$ and $1 \mathrm{c}$ are available upon request.

Table 4

Descriptive statistics of studies $1,1 b$, and $1 c$ for the complete samples as well as for individual experimental conditions (after manipulation)

\begin{tabular}{lccc}
\hline \multicolumn{1}{c}{ Measure } & Study 1 & Study 1b & Study 1c \\
\hline Sample size (after exclusion) & 163 & 109 & 199 \\
Preliminary decision (\%yes/no) & $19 / 81$ & $37.6 / 62.4$ & $29.1 / 70.9$ \\
Preliminary decision certainty (1-11) & $8.06(1.49)$ & not measured & $7.98(1.77)$ \\
$\begin{array}{l}\text { Need for further information } \\
\text { (\%yes, all conditions) }\end{array}$ & 79.1 & 76.1 & 82.4 \\
$\quad$ control & 90.9 & 78.9 & 88.2 \\
coin-congruent & 77.4 & 80.0 & 78.1 \\
$\quad$ coin-incongruent & 69.1 & 69.4 & 80.6 \\
Final decision (\%yes/no) & $11.7 / 88.3$ & $22.9 / 77.1$ & $22.1 / 77.9$ \\
Decision changed (\%, all conditions) & 11 & 14.7 & 10.1 \\
$\quad$ control & 7.3 & 15.8 & 13.2 \\
$\quad$ coin-congruent & 9.4 & 5.7 & 4.7 \\
$\quad$ coin-incongruent & 16.4 & 22.2 & 11.9 \\
Decision certainty (1-11) & $9.01(1.63)$ & $9.06(1.46)$ & $9.02(1.72)$
\end{tabular}




\begin{tabular}{lccc} 
control & & $9.00(1.51)$ & $8.94(1.65)$ \\
$\begin{array}{l}\text { coin-congruent } \\
\text { coin-incongruent }\end{array}$ & $9.09(1.40)$ & $9.09(1.82)$ \\
$\begin{array}{l}\text { Change in certainty from preliminary to final } \\
\text { decision }\end{array}$ & $.95(1.26)$ & not measured & $1.04(1.55)$ \\
control & $1.15(1.13)$ & not measured & $1.00(1.30)$ \\
coin-congruent & $.83(1.22)$ & not measured & $1.03(1.50)$ \\
coin-incongruent & $.87(1.40)$ & not measured & $1.07(1.84)$ \\
Decision difficulty $(1-7)$ & $3.23(1.68)$ & $3.05(1.67)$ & $3.40(1.85)$ \\
control & $3.13(1.50)$ & $3.18(1.75)$ & $3.50(2.02)$ \\
coin-congruent & $3.36(1.74)$ & $3.03(1.67)$ & $3.45(1.66)$ \\
coin-incongruent & $3.20(1.80)$ & $2.92(1.63)$ & $3.24(1.85)$ \\
\hline
\end{tabular}

Note. Unless otherwise noted in the measures column, the table displays means and standard deviations in brackets.

${ }^{a}$ Calculated as decision certainty minus preliminary decision certainty, i.e., positive values reflect increased certainty. 